\title{
Human B Cell Senescence in Pulmonary Infections
}

\author{
Bonnie B. Blomberg, ${ }^{* 1}$, Daniela Frasca ${ }^{1}$ and Deborah Dunn-Walters ${ }^{2}$ \\ ${ }^{1}$ Department of Microbiology and Immunology, University of Miami Miller School of Medicine, Miami, USA \\ ${ }^{2}$ Peter Gorer Department of Immunobiology, King's College, London School of Medicine, London, UK
}

\begin{abstract}
Vaccinations are powerful tools to help prevent/minimize the consequences of infections. Currently available vaccines are protecting only part of the human population because of the age-related decrease in immune functions. Vaccination against Streptococcus pneumoniae and influenza are strongly recommended in children under 2 years of age and individuals over 65 years of age to protect them from infection. However, although commercially available vaccines against these infectious diseases provide protection and ensure lasting immunological memory in children and adults, they are much less effective in elderly individuals. The mechanisms for the reduced response of the elderly to pneumococcal and influenza vaccines are discussed in this review from the perspective of deficiencies seen in B cell function with age.
\end{abstract}

Keywords: Aging, B cells, Pneumococcus, Influenza.

\section{INTRODUCTION}

Bacterial and viral pathogens play a significant role in serious infections in adults and may lead to the need for hospitalization and admission to intensive care units, especially in cases of severe respiratory distress. Streptococcus pneumoniae, influenza and parainfluenza viruses, respiratory syncytial virus, herpes viruses (including herpes zoster) and adenovirures are the most frequent causes of these severe infections and pneumonia/influenza is the $8^{\text {th }}$ leading cause of death in the United States [1].

Vaccination is the most effective tool for preventing infectious diseases. In general, vaccines elicit an immune response and consequently immunological memory that mediates protection from either the infection or the disease. Antibody production by B cells is an essential effector mechanism of protection. In this review, we will focus on vaccines against Streptococcus pneumoniae and influenza, and we will discuss how these vaccines elicit much less protection in elderly individuals than in young adults. We will also consider some of the outstanding questions regarding how to improve the immune and the effective vaccine response in the elderly, with particular emphasis on the B cell response.

\section{PNEUMOCOCCAL DISEASE IN THE ELDERLY}

Pneumococcal disease is a serious public health concern and largely affects the very young and the elderly. The most common cause is Streptococcus pneumoniae, which is a frequent coloniser of the nasopharyngeal tract without causing disease. It is an opportunistic pathogen which takes

\footnotetext{
*Address correspondence to this author at the Department of Microbiology and Immunology RMSB \#3146A, University of Miami Miller School of Medicine P.O. Box 016960 (R-138), Miami FL 33101, USA; Tel: +1-305-2436040; Fax: +1-305-2434623;

E-mail: bblomber@med.miami.edu
}

advantage of the resolution phase of influenza infection and is therefore often associated with flu. Indeed it has been suggested that many deaths attributed to influenza are actually deaths from a secondary pneumococcal infection [2]. Pulmonary pneumonia is the most frequent manifestation of infection, but the most serious is invasive pneumococcal disease, where there may be up to $30 \%$ of cases that do not involve a respiratory infection [3]. Disease incidence in the elderly is high, for invasive pneumococcal disease alone the incidence is 40 per 100,000 in the over 65 age group and $50 \%$ of these die from the disease (Fig. 1). There are many more cases of community acquired pulmonary pneumonia that are not always reported, but do contribute to increased morbidity. In the UK in 2004 more than 1 in 5 people consulted their GP for a respiratory disease; 24 million consultations, of which a third are estimated to be for infectious disease [4]. Older people recover more slowly from these infections and they may cause additional co-morbidity, for example, a significant number of adverse cardiovascular events occur within 90 days of hospitalisation for pneumonia, many occurring within 2 weeks of admission [5]. Conversely, pneumonia is itself a significant complication in hospital admissions for other causes, such as major surgery for hip fracture. The emergence of multidrug resistant strains of $S$. pneumoniae means that induction of host immunity is crucial for protection.

\section{Pneumococcal Vaccines}

It is for these reasons that vaccination of children and the older population with the pneumococcal vaccine is encouraged. Since $S$. pneumoniae is coated in protective polysaccharide the most common vaccine (PPV23) comprises 23 different polysaccharides which are thought to cover the $S$. pneumoniae serotypes responsible for $90 \%$ of infections [6]. However, since polysaccharide is a T- 


\section{a Incidence (per100,000)}
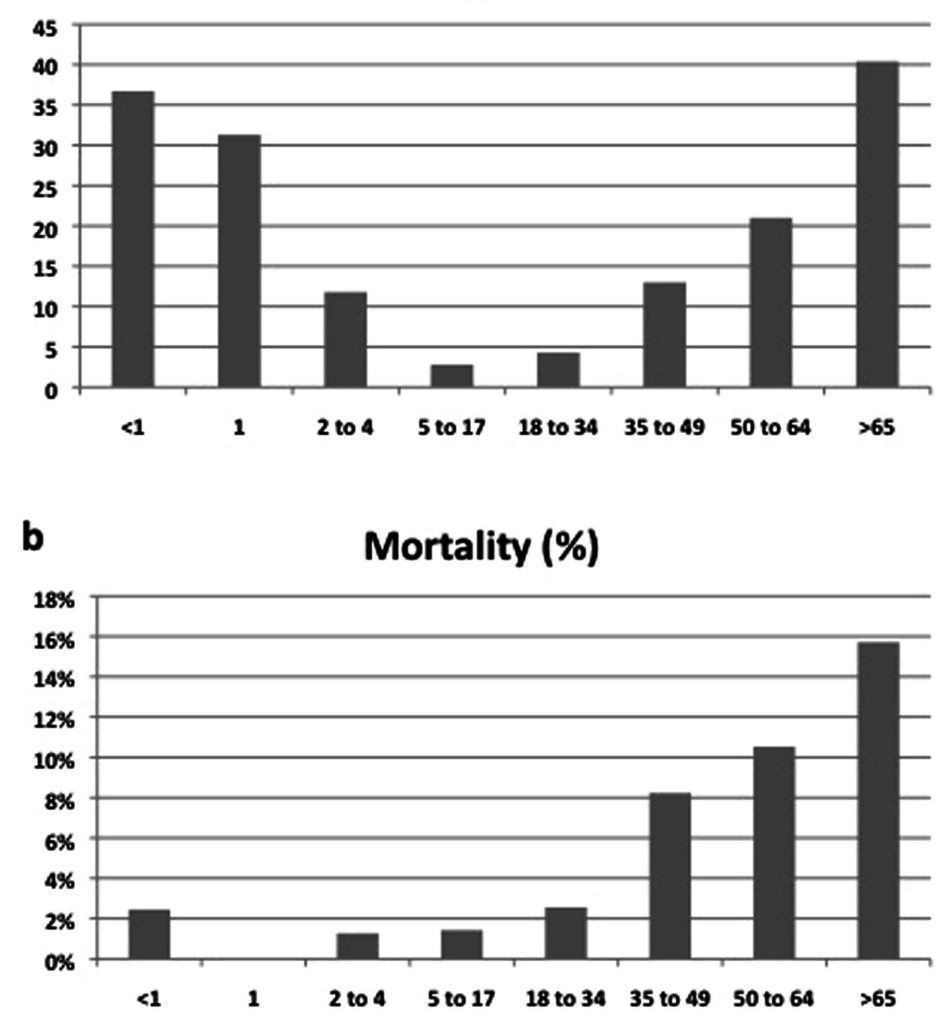

Fig. (1). Incidence (a) and mortality rates (b) of invasive pneumococcal disease by age group. Data from the ABCs areas of USA representing 28,856,774 persons in 2008 [3].

independent type II (TI2) antigen, a B cell response to this vaccine does not follow the classical T-dependent (TD) development pathway, IgG is skewed towards the IgG2 subclass and IgM responses are also thought to be key. The TI2 B cell response is elicited by antigens that consist of repeated epitopes and is still not completely understood, although it seems likely that the so-called "IgM memory" subset of B cells is involved. In man these cells are thought to be the circulating equivalent of the marginal zone $\mathrm{B}$ cells of the spleen, which are of the IgM isotype but show evidence of somatic hypermutation in their immunoglobulin genes and protect against $S$. pneumoniae [7]. Their origins and function remain a matter of considerable debate [8, 9]. A reliance on splenic marginal zone cells would help explain the poor response to pure polysaccharide vaccine in the very young, since this B cell compartment is not fully formed in humans until 2 years of age [10]. The use of a conjugate vaccine (PCV), to help activate the TD pathway of development, has certainly helped improve efficacy of the vaccine in infants and this is now the recommendation. However, there are no major changes in the size of the marginal zone of the spleen in old age [11], and there are conflicting reports as to whether IgM memory levels change with age [12-14], so the reasons for the increased pneumococcal susceptibility of the very young and the old may be different.

The PPV23 protects younger adults from pneumococcal disease but is much less effective in the elderly. While there is no doubt that the vaccine does help protect against invasive pneumococcal disease, and is therefore currently recommended for the older population [15], its protection against community acquired pneumonia is extremely poor [16]. Results from the use of different vaccination protocols that include the PCV vaccine, either on its own or in combination with the PPV23 as prime and boost, are controversial [17-20]. Indeed concerns have been raised that boosting or revaccination might result in hyporesponsiveness [21]. However, there have been a number of recent studies that suggest revaccination is effective and generally well tolerated [22-24]. It must be remembered that the response is not a TD recall memory response and if there is a gradual age-related decrease in effectiveness to PPV23 vaccination, then a challenge 5 or 6 years later might be expected to be slightly lower in the over 65's due to increased age, regardless of whether subjects had been previously vaccinated. These concerns, together with the poor effectiveness of vaccine in older people, have lead the UK Joint Committee on Vaccination and Immunisation to withdraw their previous recommendation that the individuals over 65 years of age should receive the pneumococcal vaccine [25]. At the present time it seems as if the best way of reducing pneumococcal disease in the elderly is by ensuring effective vaccination of children and thereby providing herd immunity [25, 26].

\section{Correlates of Protection}

One of the main problems in the study of these vaccines is that of not having good correlates of protection in order to 
measure their efficacy. The easiest, and most commonly used, measurement of the immune response is to measure the pneumococcal-specific IgG serum antibodies by ELISA, since IgG is by far the most abundant antibody produced in response to the vaccine. However, although the protection in elderly is reduced, and there are some reports that IgG levels are decreased [27], many reports seem to find similar levels of pneumococcal-specific IgG in older people (Fig. 2) [28,
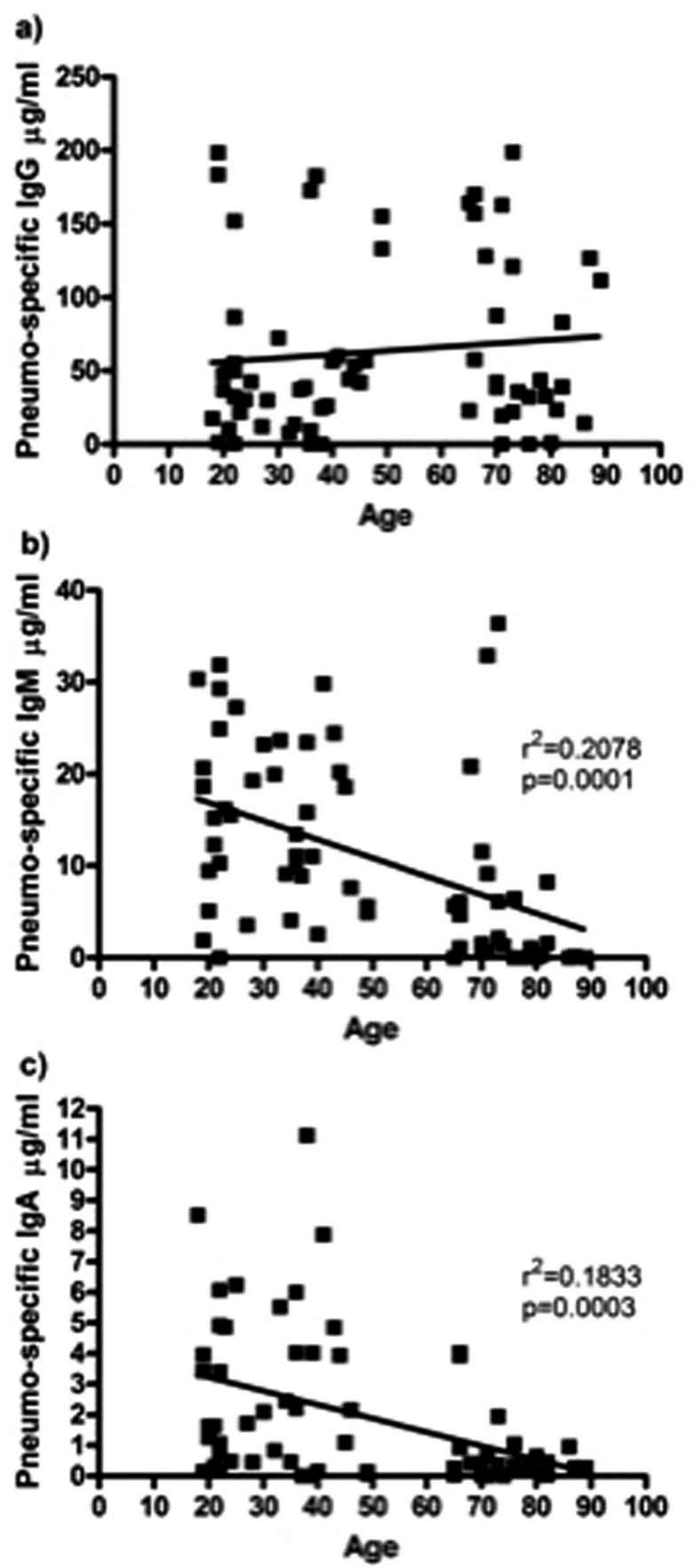

Fig. (2). Pneumococcal-specific serum antibody. Showing the peak increase in pneumococcal specific antibody (value at peak less value pre-vaccination) versus age of subject a) IgG at day $28, \mathbf{b}$ ) IgM at day 28, c) IgA at day 7. Pearson’s correlation statistics.
29]. Fig. (2) shows values where the pre-existing amounts at t0 were subtracted from the post-vaccination concentrations. The statistical significance of the correlations remains the same, i.e. not significant for IgG and significant for IgM and IgA, even if the pre-existing values were not subtracted (data not shown). Hence levels of pneumococcal-specific IgG seem to correlate with protection in young adults but not in the old, therefore IgG ELISA may not be the most appropriate correlate of vaccine efficacy. The opsonophagocytic assay is a functional assay that may be a better reflection of the efficacy of the antibody response in vivo [30]. This assay uses total serum and so may not necessarily reflect the activity of total IgG. While the levels of specific IgG that are induced in response to pneumococcal vaccination may not significantly differ with age, there is no question that the levels of opsonophagocytic activity do [2832]. Therefore it is worth looking at other factors that may be relevant. In vivo the decreased phagocytic abilities of macrophages and neutrophils are likely to be highly relevant, although this would not be relevant in the in vitro assays. While there is some controversy over whether levels of complement change with age, reports are either that they remain unchanged or they increase [32], so a lack of complement is not likely to be a cause of reduced opsonophagocytic activity. Since it has been shown in both mice and humans that the classical pathway is the dominant complement pathway required for protection from $S$. pneumoniae infection [33,34], the quality of antibody is a prime consideration.

\section{Relevant Classes of Antibody}

In spite of the fact that TI2 responses would predispose towards IgG $_{2}$ in humans, not many studies look at different subclasses of IgG. Children make more IgG $_{1}$ in response to pneumococcal vaccination than adults, and there are indications that within adults there may be differences in the ratio of $\operatorname{IgG}_{1} / \operatorname{IgG}_{2}$ with age so this may be pertinent [35]. Perhaps more importantly, from the point of view of protection against pulmonary disease, IgA antibody may also contribute to protection. IgA is crucial for protection of mucosal barriers, is induced after pneumococcal vaccination in humans [36] and has been shown to control S. pneumoniae nasal colonisation in mice [37]. Data from our lab and others show that although the levels of pneumococcal-specific IgA are considerably lower than IgG, there are significant reductions in IgA with age [38, 39]. The biggest difference appears to be in the week immediately following the vaccine challenge, thereafter the young adults do not further increase serum antibody and by day 28 the age-related difference is negligible [39]. Hence differences in IgA responses may help explain the ageing immune response, although perhaps not via differences in opsonic ability since removal of up to $80 \%$ of the IgA antibodies from sera at day 28 after vaccination had no effect [38]. In contrast, removal of IgM had a significant effect on the opsonic capability of the sera. It was thought that even though the IgM levels are much lower than IgG, their much greater efficiency could mean that the failure of opsonophagocytosis in old age could be due to changes in IgM [38]. Pneumococcal-specific IgM levels have been shown to be significantly reduced with age at both 
1 week, 2 weeks and 4 weeks after vaccination [14, 39]. Furthermore, a decrease of naturally acquired pneumococcalspecific IgM antibodies in older people, in the absence of any vaccination, has been shown [31].

While some pneumococcal-specific IgM antibodies are known to be in germline configuration and polyreactive for different serotypes [40, 41], implying a possible origin from naïve B cells, others may well be derived from IgM memory cells $[7,10]$ as discussed above. Indeed the use of a humanised SCID mouse model has demonstrated that IgM antibody is largely made by the CD27+ IgM+ subset rather than the naïve CD27- IgM+ cells [42]. Human B1 cells have recently been reported to be in the IgM memory subset [43] and may well be important in the response. It is also interesting that many pneumococcal-specific antibodies are encoded by IGHV3 family genes $[44,45]$ and although the IGHV3 family is the most used in all B cell subgroups it is overrepresented in IgM memory cells [46].

It must be remembered that there over 90 different serotypes of $S$. pneumoniae and that our current vaccines use between 7 and 23 of them. As we increase vaccine coverage we also inadvertently change the prevalence of different serotypes in the population [47]. In addition, polysaccharide responses do not appear to be persistent and require revaccination. Thus, although strategies to improve vaccine responses in the elderly are important, it is also imperative to determine the underlying cause for their immunodeficiency, as a therapy for this may have a more significant effect for the population in the longer term.

\section{INFLUENZA IN THE ELDERLY}

Influenza is associated with morbidity and mortality in individuals over 65 years of age, children under 2 years and individuals at high risk for complications from influenza because of other co-morbidities such as immunodeficiency diseases, ischaemic heart disease, cerebrovascular disease, diabetes [48]. The complications of influenza may include secondary bacterial infections and exacerbations of preexisting medical conditions [48, 49]. Hospitalization has been described as a major contributor to the development of disability in elderly individuals [50]. This decline in physical activities and consequent disability represent a significant economic burden due to both direct (medical) and indirect costs (inability to work, reduction in productivity) [51]. Influenza epidemics are associated with approximately 200,000 estimated hospitalizations and 36,000 deaths each year in the United States [52].

\section{Influenza Vaccines}

Although antiviral drugs against influenza are available, vaccination is the most effective method of preventing influenza infection and disease. There are two types of vaccines available in the United States: trivalent inactivated vaccine (TIV) and live attenuated vaccine (LAV). Both vaccines contain two influenza A viruses (H1N1 and H3N2) plus influenza B virus. The TIV, produced by several manufacturers, is licensed worldwide and recommended for many populations, including the high risk groups mentioned above. TIV is widely used for the prevention of influenza and has been available for more than 60 years [51]. For this vaccine, the serum antibody response after vaccination correlates with protection against subsequent influenza infection [53]. Although intranasal administration of LAV has also been shown to induce a robust serum and mucosal antibody response in children and adults, the magnitude of the influenza-specific antibody response in serum is much lower than that elicited by TIV [54].

The influenza vaccine induces an antiviral response in B and $\mathrm{T}$ cells, resulting in humoral and cellular immunity, respectively [55]. Vaccine-activated $\mathrm{T}$ cells stimulate B cells to differentiate and secrete antibodies specific for a particular vaccine strain. The antibody response to the vaccine is the first line of defense against subsequent influenza infection. The specific antibodies bind to the surface glycoproteins hemagglutinin (HA) and neuraminidase (NA), to neutralize the virus particle [56, 57]. Secretory IgA and IgM provide protection against the establishment of initial infection, however, IgG neutralizes newly replicating virus once infection has been established [58]. Annual influenza vaccinations help the human host to make protective levels of antibodies against the currently circulating strains [59, 60]. Although for long time a general consensus has existed that there is little or no pre-existing immunity to newly emerging influenza variants in human beings [59, 60], recently it has been shown that seasonal influenza vaccination can induce polyclonal heterosubtypic neutralizing antibodies which are cross-reactive with both the swine-origin pandemic $\mathrm{H} 1 \mathrm{~N} 1$ virus and the $\mathrm{H} 5 \mathrm{~N} 1$ avian virus [61].

The effects of influenza vaccination are different in individuals of different ages [62-66] and successive annual vaccinations increase protection against influenza [67-69]. In the case of seasonal influenza vaccination there is evidence that elderly individuals who have routinely received the vaccine can still contract the infection, with secondary complications leading to hospitalization, physical debilitation, exacerbation of underlying medical conditions and death [70-72]. This is likely due to some elderly individuals having a more compromized immune system. Moreover, antigenic drift, resulting in a mismatch between the virus strain in the vaccine and the circulating virus strain, can also cause reduced vaccine effectiveness [73]. The fact that the influenza vaccines also prevent complications from influenza (e.g. pneumonia) strongly supports vaccination campaigns targeted to improve immune functions in elderly individuals. Current influenza vaccination campaigns are able to reduce hospitalization to some extent [74], but rates of hospitalizations due to influenza-related disease are still high [69], likely due to reasons above.

\section{Influenza Vaccination and the Immune Response}

The age-dependent differences in the response to influenza vaccination depend on age-related differences in the innate and adaptive systems [64, 75-78]. These include reduced natural killer cell cytotoxicity on a per cell basis [79], reduced number and/or function of dendritic cells in blood [78, 80-82], decreased $\mathrm{T}$ cell function [82-87], loss of CD28 expression [88], cytomegalovirus (CMV) positivity 
[89, 90], decreased memory B cells [13, 14, 91, 92] and reduced specificity and class of antibody produced [93, 94]. Most of the studies conducted so far have shown that the reduced response of the elderly to influenza vaccination is correlated with the decrease in $\mathrm{T}$ cell functions, in particular CD8+ T cells [55, 83, 86, 95, 96]. Moreover, the frequencies of CD8+CD28- $\mathrm{T}$ cells have been proposed as biological markers of compromised immune competence, identifying individuals at risk for insufficient antibody responses [83]. Others have shown that the levels of interferon- $\gamma$ (IFN- $\gamma$ ), interleukin-10 (IL-10) and Granzyme levels increase after influenza infection, and in young individuals more than in the elderly. These responses are specific for the infecting strain and can be used to predict the immune response to influenza vaccination and infection [96].

\section{Influenza Vaccination and B Cell Response}

Only a few studies have evaluated possible age-related intrinsic defects in the B cell-specific response to influenza vaccination. In a study recently published [97], we have evaluated the serum response to seasonal influenza vaccination in subjects of different ages and associated this with the specific $B$ cell response to the vaccine in vitro. Briefly, we have stimulated peripheral blood-derived B cells with the autologous vaccine in vitro for 7 days to induce activation-induced cytidine deaminase (AID). AID is present only in activated (vaccine-stimulated) B cells, is a good measure of B cell function [13], including vaccine-specific responses. Our results obtained during the 2008-2009 and the 2009-2010 seasonal influenza vaccination show that the specific AID response of B cells to the influenza vaccine given in vitro and the in vivo serum response to vaccination (as evaluated by the hemagglutination inhibition assay, HAI) are correlated and are decreased with age [97]. Moreover, the ex vivo percentage of switch memory $\mathrm{B}$ cells and their increase after vaccination are also correlated and are decreased with age [97] (Table 1 and Fig. 3). Data presented in Fig. (3), showing that the fold-increase in HAI serum response and in the percentage of switch memory B cells are correlated, have been obtained from a limited number of individuals vaccinated during the 2009-2010 seasonal flu vaccine campain. However, we have data consistent with the results in Fig. (3) for the pandemic (p) H1N1 vaccine response (Frasca, et al.,).

\section{NOTE ADDED IN PROOF}

Although we have not measured vaccine-specific switch memory B cells, their percentage increases only if the

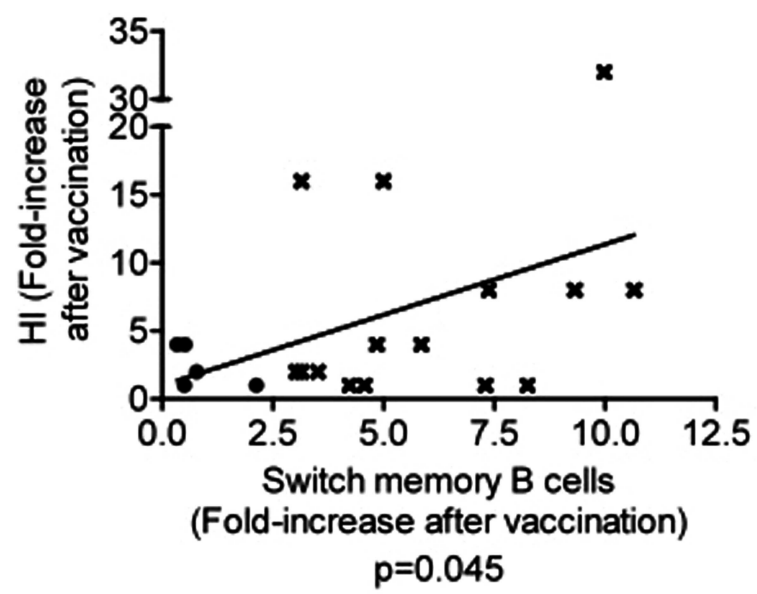

Fig. (3). The serum response and the ex vivo generation of switch memory B cells are correlated. Sera were analyzed in HAI assay to evaluate antibody production to vaccine. Switch memory B cells are CD19+CD27+IgG+IgA+. The same subjects presented in Table $\mathbf{1}$ are evaluated. Fold-increases in HAI are: $7.9 \pm 2.1$ (young) and 2.0 \pm 0.3 (elderly). Fold-increases in switch memory B cell percentages are: $2.4 \pm 0.2$ (young) and $0.9 \pm 0.3$ (elderly). The differences between the 2 groups are significant ( $\mathrm{p}=0.0385$ for HAI and $\mathrm{p}=0.0455$ for switch memory B cell percentages).

Table 1. The in vitro AID Response to the Vaccine Tracks with the Serum Response

\begin{tabular}{|c|c|c|}
\hline Groups & Number of Subjects in Each Group & Mean Age \pm SE (Range) \\
\hline \hline $\mathrm{HAI}>4 / \mathrm{AID}>2$ & 12 & $35 \pm 4(22-60)$ \\
\hline $\mathrm{HAI}<4 / \mathrm{AID}<2$ & 13 & $65 \pm 6(22-89)$ \\
\hline $\mathrm{HAI}>4 / \mathrm{AID}<2$ & 7 & $45 \pm 7(28-72)$ \\
\hline $\mathrm{HAI}<4 / \mathrm{AID}>2$ & 5 & $40 \pm 7(28-56)$ \\
\hline
\end{tabular}

Sera isolated from subjects of different ages, before (t0) or after vaccination (t28), were collected and analyzed in HAI assay to evaluate antibody production to vaccine. Results are expressed as fold-increase after vaccination. HAI $>4$ means a positive seroconversion. B cells $\left(10^{6}\right.$ cells/ml), isolated from the peripheral blood of the same subjects, before (t0) or after vaccination (t28), were cultured with the vaccine, for 7 days. At the end of this time, cells were harvested and qPCR run to evaluate AID mRNA expression. AID $>2$ means a positive response in vitro to the vaccine. Thirty-seven subjects were evaluated, 29 young and 8 old. Most of the subjects $(68 \%)$ fall within the first two groups ( $<<0.05)$ by $\chi^{2}$. Kruskal-Wallis analysis was performed to examine whether there was a discernible pattern of age between groups. The group HAI $<4 /$ AID $<2$, had most of the elderly in the study $(\mathrm{p}<0.001)$ 
individuals have been vaccinated. Our results, showing that switch memory B cells are increased by influenza vaccination, are of great importance because memory B cells can carry the history of the individual in terms of specificimmune responses [98]. In an antigen-specific response, memory B cells undergo massive expansion and can differentiate into either short-lived plasma cells, or plasma cells in response to polyclonal stimuli or homeostatic mechanisms [99]. Some of the short-lived plasma cells will eventually become long-lived plasma cells if rescued in available niches, such as bone marrow [100]. In this homeostatic response all memory B cells could undergo continuous proliferation and differentiation and become plasmablasts, contributing to a serum pool of specific antibodies which could theoretically be maintained throughout a human life-span. Although the major preinfection protection against viruses is by the neutralising activity of antibodies, the antibody response of elderly individuals may not be sufficient to adequately prevent a new virus infection. We also evaluated whether B cellspecific immunological parameters could predict poor antiinfluenza virus vaccine responses and therefore can be used as biological markers of immune senescence. Our data demonstrate that the in vitro vaccine-specific AID response correlates with an optimal HAI serum response in most of the subjects [97], Frasca et. al 2011, submitted]. Moreover, we have also shown that the AID response to $\mathrm{CpG}$ at t0 (before vaccination) can predict an optimal vaccine response. Memory B cells and plasmablasts have been correlated with serum antibody levels in another study conducted in children (6 months-4 years and 5-9 years of age) and adults, where younger children responded to TIV less than older children and less than adults [101]. The same group recently showed that the age-related decrease in the serum $\mathrm{pH} 1 \mathrm{~N} 1$ vaccine response is due to the reduction in the number of responding plasmablasts and hence plasmablast-derived polyclonal antibodies are dramatically reduced in elderly individuals compared with these in young individuals [102]. We have also found (Frasca et al 2011, submitted) that switch memory B cells (CD19+CD27+IgG+IgA+) increase after pH1N1 vaccination at t28 and the fold-increase correlates with the optimal HAI serum response. Moreover, the percentage of switch memory $\mathrm{B}$ cells at t0 also correlates with the HAI response. Therefore, we have suggested that these switch memory B cells may be used as a predictive marker for optimal B cell responsiveness, in addition to the AID response to $\mathrm{CpG}$ at t0.

\section{CONCLUSIONS}

It is clear that we do not yet fully understand the immune response to a TI2 antigen such as pneumococcal polysaccharide in humans and therefore it is imperative that we investigate this in future in order to determine the mechanistic basis for age-related change in pneumococcal responses. Particularly of interest are the IgM+CD27+ B cells, that may include B1 B cells, and which have been reported to decrease with age. Once we understand the mechanisms we may be able to design therapies and better vaccine strategies for the ageing immune system. Until then we should take account of the nature of the TI2 response in our vaccine studies and measure IgM, IgA and IgG subclasses and/or opsonophagocytic assays when looking for correlates of protection. As to the response to the influenza vaccines, these are TD responses that induce IgG specific antibodies. Although these responses require $\mathrm{T}$ cell help, autonomous B cell defects have been described in elderly individuals and correlate with the specific antibody response. The deficiencies include AID and switch memory B cells. These biomarkers should be able to measure possible improvement in the response to the influenza vaccine after intervention with either adjuvants or lifestyle changes.

\section{CONFLICT OF INTEREST}

None declared.

\section{ACKNOWLEDGEMENTS}

None declared.

\section{REFERENCES}

[1] Centers for Disease control and Prevention [home page on the internet] Available from: http://www.cdc.gov/nchs/fastats/lcod.htm

[2] van der Sluijs KF, van der Poll T, Lutter R, Juffermans NP, Schultz MJ. Bench-to-bedside review: bacterial pneumonia with influenza pathogenesis and clinical implications. Crit Care 2010; 14: 219.

[3] CDC Active Bacterial Core Surveillance (ABCs) Report, Emerging Infections Program Network, Streptococcus Pneumoniae. 2008 [home page on the internet] Available from: http://www.cdc.gov/ abcs/reports-findings/survreports/spneu08.pdf

[4] British Thoracic- Society [home page on the internet] Available from: http://www.britthoracic.org.uk/Portals/0/Library/BTS\%20 Publications/burdeon_of_lung_disease2007.pdf

[5] Perry TW, Pugh MJ, Waterer GW, et al. Incidence of cardiovascular events after hospital admission for pneumonia. Am J Med 2011; 124: 244-51.

[6] Robbins JB, Austrian R, Lee CJ, et al. Considerations for formulating the second-generation pneumococcal capsular polysaccharide vaccine with emphasis on the cross-reactive types within groups. J Infect Dis 1983; 148: 1136-59.

[7] Kruetzmann S, Rosado MM, Weber H, et al. Human immunoglobulin M memory B cells controlling Streptococcus pneumoniae infections are generated in the spleen. J Exp Med 2003; 197: 93945.

[8] Kurosaki T, Aiba Y, Kometani K, Moriyama S, Takahashi Y. Unique properties of memory B cells of different isotypes. Immunol Rev 2010; 237: 104-16.

[9] Tangye SG, Good KL. Human IgM+CD27+ B cells: memory B cells or "memory" B cells? J Immunol 2007; 179: 13-9.

[10] Timens W, Boes A, Rozeboom-Uiterwijk T, Poppema S. Immaturity of the human splenic marginal zone in infancy. Possible contribution to the deficient infant immune response. J Immunol 1989; 143: 3200-6.

[11] Banerjee M, Sanderson JD, Spencer J, Dunn-Walters DK. Immunohistochemical analysis of ageing human B and T cell populations reveals an age-related decline of CD8 T cells in spleen but not gut-associated lymphoid tissue (GALT). Mech Ageing Dev 2000; 115: 85-99.

[12] Colonna-Romano G, Aquino A, Bulati M, et al. Memory B cell subpopulations in the aged. Rejuvenation Res 2006; 9: 149-52.

[13] Frasca D, Landin AM, Lechner SC, et al. Aging down-regulates the transcription factor E2A, activation-induced cytidine deaminase, and Ig class switch in human B cells. J Immunol 2008; 180: 528390.

[14] Shi Y, Yamazaki T, Okubo Y, Uehara Y, Sugane K, Agematsu K. Regulation of aged humoral immune defense against pneumococcal bacteria by IgM memory B cell. J Immunol 2005; 175: 3262-7. 
[15] Vila-Corcoles A, Ochoa-Gondar O, Guzman JA, Rodriguez-Blanco T, Salsench E, Fuentes CM. Effectiveness of the 23-valent polysaccharide pneumococcal vaccine against invasive pneumococcal disease in people 60 years or older. BMC Infect Dis 2010; 10: 73.

[16] Dominguez A, Izquierdo C, Salleras L, et al. Effectiveness of the pneumococcal polysaccharide vaccine in preventing pneumonia in the elderly. Eur Respir J 2010; 36: 608-14.

[17] Baxendale HE, Johnson M, Keating SM, et al. Circulating pneumococcal specific plasma and memory B cells in the elderly two years after pneumococcal conjugate versus polysaccharide vaccination. Vaccine 2010; 28: 6915-22.

[18] Baxendale HE, Keating SM, Johnson M, Southern J, Miller E, Goldblatt D. The early kinetics of circulating pneumococcalspecific memory $\mathrm{B}$ cells following pneumococcal conjugate and plain polysaccharide vaccines in the elderly. Vaccine 2010; 28: 4763-70.

[19] de Roux A, Schmole-Thoma B, Siber GR, et al. Comparison of pneumococcal conjugate polysaccharide and free polysaccharide vaccines in elderly adults: conjugate vaccine elicits improved antibacterial immune responses and immunological memory. Clin Infect Dis 2008; 46: 1015-23.

[20] Goldblatt D, Southern J, Andrews N, et al. The immunogenicity of 7-valent pneumococcal conjugate vaccine versus 23-valent polysaccharide vaccine in adults aged 50-80 years. Clin Infect Dis 2009; 49: 1318-25.

[21] O'Brien KL, Hochman M, Goldblatt D. Combined schedules of pneumococcal conjugate and polysaccharide vaccines: is hyporesponsiveness an issue? Lancet Infect Dis 2007; 7: 597-606.

[22] Musher DM, Manof SB, Liss C, et al. Safety and antibody response, including antibody persistence for 5 years, after primary vaccination or revaccination with pneumococcal polysaccharide vaccine in middle-aged and older adults. J Infect Dis 2010; 201: 516-24.

[23] Nichol KL. Pneumococcal vaccination and revaccination in the elderly population. J Infect Dis 2010; 201: 659-61.

[24] Torling J, Hedlund J, Konradsen HB, Ortqvist A. Revaccination with the 23-valent pneumococcal polysaccharide vaccine in middle-aged and elderly persons previously treated for pneumonia. Vaccine 2003; 22: 96-103.

[25] Joint Committee on Vaccination and Immunisation. Statements, advice and recommendations. Department of Health. [Update: $9^{\text {th }}$ July 2011] Available from: http://www.dh.gov.uk/ab/JCVI/DH_ 094744

[26] Simonsen L, Taylor RJ, Young-Xu Y, Haber M, May L, Klugman KP. Impact of pneumococcal conjugate vaccination of infants on pneumonia and influenza hospitalization and mortality in all age groups in the United States. MBio 2011; 2(1): e00309-10.

[27] Romero-Steiner S, Musher DM, Cetron MS, et al. Reduction in functional antibody activity against Streptococcus pneumoniae in vaccinated elderly individuals highly correlates with decreased IgG antibody avidity. Clin Infect Dis 1999; 29: 281-8.

[28] Musher DM, Groover JE, Rowland JM, et al. Antibody to capsular polysaccharides of Streptococcus pneumoniae: prevalence, persistence, and response to revaccination. Clin Infect Dis 1993; 17: 6673.

[29] Rubins JB, Puri AK, Loch J, et al. Magnitude, duration, quality, and function of pneumococcal vaccine responses in elderly adults. $\mathrm{J}$ Infect Dis 1998; 178: 431-40.

[30] Romero-Steiner S, Libutti D, Pais LB, et al. Standardization of an opsonophagocytic assay for the measurement of functional antibody activity against Streptococcus pneumoniae using differentiated HL-60 cells. Clin Diagn Lab Immunol 1997; 4: 415-22.

[31] Simell B, Lahdenkari M, Reunanen A, Kayhty H, Vakevainen M. Effects of ageing and gender on naturally acquired antibodies to pneumococcal capsular polysaccharides and virulence-associated proteins. Clin Vaccine Immunol 2008; 15: 1391-7.

[32] Simell B, Vuorela A, Ekstrom N, et al. Aging reduces the functionality of anti-pneumococcal antibodies and the killing of Streptococcus pneumoniae by neutrophil phagocytosis. Vaccine 2011; 29: 1929-34.
[33] Brown JS, Hussell T, Gilliland SM, et al. The classical pathway is the dominant complement pathway required for innate immunity to Streptococcus pneumoniae infection in mice. Proc Natl Acad Sci USA 2002; 99: 16969-74.

[34] Yuste J, Sen A, Truedsson L, et al. Impaired opsonization with C3b and phagocytosis of Streptococcus pneumoniae in sera from subjects with defects in the classical complement pathway. Infect Immun 2008; 76: 3761-70.

[35] Lottenbach KR, Mink CM, Barenkamp SJ, Anderson EL, Homan SM, Powers DC. Age-associated differences in immunoglobulin G1 (IgG1) and IgG2 subclass antibodies to pneumococcal polysaccharides following vaccination. Infect Immun 1999; 67: 4935-8.

[36] Lue C, Tarkowski A, Mestecky J. Systemic immunization with pneumococcal polysaccharide vaccine induces a predominant IgA2 response of peripheral blood lymphocytes and increases of both serum and secretory anti-pneumococcal antibodies. J Immunol 1988; 140: 3793-800.

[37] Fukuyama Y, King JD, Kataoka K, et al. Secretory-IgA antibodies play an important role in the immunity to Streptococcus pneumoniae. J Immunol 2010; 185: 1755-62.

[38] Park S, Nahm MH. Older adults have a low capacity to opsonize pneumococci due to low IgM antibody response to pneumococcal vaccinations. Infect Immun 2011; 79: 314-20.

[39] Ademokun A, Wu YC, Martin V, et al. Vaccination-induced changes in human B cell repertoire and pneumococcal IgM and IgA antibody at different ages. Ageing Cell 2011; 10(6): 922-30.

[40] Baxendale HE, Davis Z, White HN, Spellerberg MB, Stevenson FK, Goldblatt D. Immunogenetic analysis of the immune response to pneumococcal polysaccharide. Eur J Immunol 2000; 30: 121423.

[41] Baxendale HE, Johnson M, Stephens RC, et al. Natural human antibodies to pneumococcus have distinctive molecular characteristics and protect against pneumococcal disease. Clin Exp Immunol 2008; 151: 51-60.

[42] Moens L, Wuyts M, Meyts I, De Boeck K, Bossuyt X. Human memory B lymphocyte subsets fulfill distinct roles in the antipolysaccharide and anti-protein immune response. J Immunol 2008; 181: 5306-12.

[43] Griffin DO, Holodick NE, Rothstein TL. Human B1 cells in umbilical cord and adult peripheral blood express the novel phenotype CD20+ CD27+ CD43+ CD70. J Exp Med 2011; 208: 67-80.

[44] Zhou J, Lottenbach KR, Barenkamp SJ, Lucas AH, Reason DC. Recurrent variable region gene usage and somatic mutation in the human antibody response to the capsular polysaccharide of Streptococcus pneumoniae type 23F. Infect Immun 2002; 70: 4083-91.

[45] Zhou J, Lottenbach KR, Barenkamp SJ, Reason DC. Somatic hypermutation and diverse immunoglobulin gene usage in the human antibody response to the capsular polysaccharide of Streptococcus pneumoniae Type 6B. Infect Immun 2004; 72: 3505-14.

[46] Wu YC, Kipling D, Leong HS, Martin V, Ademokun AA, DunnWalters DK. High-throughput immunoglobulin repertoire analysis distinguishes between human IgM memory and switched memory B-cell populations. Blood 2010; 116: 1070-8.

[47] Zangeneh TT, Baracco G, Al-Tawfiq JA. Impact of conjugate pneumococcal vaccines on the changing epidemiology of pneumococcal infections. Expert Rev Vaccines 2011; 10: 345-53.

[48] Loerbroks ASC, Bosch JA, Litaker DG, Apfelbacher CJ. Influenza vaccination coverage among high-risk groups in 11 European countries. Eur J Public Health 2011. [Epub ahead of print].

[49] Zimmerman RK, Lauderdale DS, Tan SM, Wagener DK. Prevalence of high-risk indications for influenza vaccine varies by age, race, and income. Vaccine 2010; 28: 6470-7.

[50] Ferrucci L, Guralnik JM, Pahor M, Corti MC, Havlik RJ. Hospital diagnoses, Medicare charges, and nursing home admissions in the year when older persons become severely disabled. JAMA 1997; 277: 728-34.

[51] Monto AS, Ansaldi F, Aspinall R, et al. Influenza control in the 21st century: Optimizing protection of older adults. Vaccine 2009; 27: 5043-53. 
[52] Fiore AE, Uyeki TM, Broder K, et al. Prevention and control of influenza with vaccines: recommendations of the Advisory Committee on Immunization Practices (ACIP), 2010. MMWR Recomm Rep 2011; 59: 1-62.

[53] Couch RB, Kasel JA. Immunity to influenza in man. Annu Rev Microbiol 1983; 37: 529-49.

[54] Belshe RB, Gruber WC, Mendelman PM, et al. Correlates of immune protection induced by live, attenuated, cold-adapted, trivalent, intranasal influenza virus vaccine. J Infect Dis 2000; 181: 1133-7.

[55] Murasko DM, Bernstein ED, Gardner EM, et al. Role of humoral and cell-mediated immunity in protection from influenza disease after immunization of healthy elderly. Exp Gerontol 2002; 37: 42739.

[56] Epstein SL, Misplon JA, Lawson CM, Subbarao EK, Connors M, Murphy BR. Beta 2-microglobulin-deficient mice can be protected against influenza A infection by vaccination with vacciniainfluenza recombinants expressing hemagglutinin and neuraminidase. J Immunol 1993; 150: 5484-93.

[57] Saelens X, Vanlandschoot P, Martinet W, et al. Protection of mice against a bent assay after primary or secondary infection of humans with influenza A virus. Infect Immun 1983; 41: 540-5.

[59] McMurry JA, Johansson BE, De Groot AS. A call to cellular \& humoral arms: enlisting cognate $\mathrm{T}$ cell help to develop broadspectrum vaccines against influenza A. Hum Vaccin 2008; 4: 14857.

[60] Wrammert J, Smith K, Miller J, et al. Rapid cloning of highaffinity human monoclonal antibodies against influenza virus. Nature 2008; 453: 667-71.

[61] Corti D, Suguitan AL Jr., Pinna D, et al. Heterosubtypic neutralizing antibodies are produced by individuals immunized with a seasonal influenza vaccine. J Clin Invest 2010; 120: 1663-73.

[62] Goodwin K, Viboud C, Simonsen L. Antibody response to influenza vaccination in the elderly: a quantitative review. Vaccine 2006; 24: 1159-69.

[63] McElhaney JE. Influenza vaccine responses in older adults. Ageing Res Rev 2011; 10(3): 379-88.

[64] McElhaney JE, Effros RB. Immunosenescence: what does it mean to health outcomes in older adults? Curr Opin Immunol 2009; 21: 418-24.

[65] Simonsen L, Taylor RJ, Viboud C, Miller MA, Jackson LA. Mortality benefits of influenza vaccination in elderly people: an ongoing controversy. Lancet Infect Dis 2007; 7: 658-66.

[66] Targonski PV, Jacobson RM, Poland GA. Immunosenescence: role and measurement in influenza vaccine response among the elderly. Vaccine 2007; 25: 3066-9.

[67] Ahmed AE, Nicholson KG, Nguyen-Van-Tam JS. Reduction in mortality associated with influenza vaccine during 1989-90 epidemic. Lancet 1995; 346: 591-5.

[68] Keitel WA, Cate TR, Couch RB. Efficacy of sequential annual vaccination with inactivated influenza virus vaccine. Am J Epidemiol 1988; 127: 353-64.

[69] Thompson WW, Shay DK, Weintraub E, et al. Influenza-associated hospitalizations in the United States. JAMA 2004; 292: 1333-40.

[70] Gross PA, Hermogenes AW, Sacks HS, Lau J, Levandowski RA. The efficacy of influenza vaccine in elderly persons. A metaanalysis and review of the literature. Ann Intern Med 1995; 123: 518-27.

[71] Simonsen L, Clarke MJ, Schonberger LB, Arden NH, Cox NJ, Fukuda K. Pandemic versus epidemic influenza mortality: a pattern of changing age distribution. J Infect Dis 1998; 178: 53-60.

[72] Vu T, Farish S, Jenkins M, Kelly H. A meta-analysis of effectiveness of influenza vaccine in persons aged 65 years and over living in the community. Vaccine 2002; 20: 1831-6.

[73] Legrand J, Vergu E, Flahault A. Real-time monitoring of the influenza vaccine field effectiveness. Vaccine 2006; 24: 6605-11.

[74] Nichol KL, Margolis KL, Wuorenma J, Von Sternberg T. The efficacy and cost effectiveness of vaccination against influenza among elderly persons living in the community. N Engl J Med 1994; 331: 778-84.
[75] DelaRosa O, Pawelec G, Peralbo E, et al. Immunological biomarkers of ageing in man: changes in both innate and adaptive immunity are associated with health and longevity. Biogerontology 2006; 7: 471-81.

[76] Effros RB. Genetic alterations in the ageing immune system: impact on infection and cancer. Mech Ageing Dev 2003; 124: 71-7.

[77] Franceschi C, Valensin S, Bonafe M, et al. The network and the remodeling theories of aging: historical background and new perspectives. Exp Gerontol 2000; 35: 879-96.

[78] Shaw AC, Joshi S, Greenwood H, Panda A, Lord JM. Aging of the innate immune system. Curr Opin Immunol 2010; 22: 507-13.

[79] Solana R, Pawelec G, Tarazona R. Aging and innate immunity. Immunity 2006; 24: 491-4.

[80] Jing Y, Shaheen E, Drake RR, Chen N, Gravenstein S, Deng Y. Aging is associated with a numerical and functional decline in plasmacytoid dendritic cells, whereas myeloid dendritic cells are relatively unaltered in human peripheral blood. Hum Immunol 2009; 70: 777-84.

[81] Panda A, Qian F, Mohanty S, et al. Age-associated decrease in TLR function in primary human dendritic cells predicts influenza vaccine response. J Immunol 2010; 184: 2518-27.

[82] Sridharan A, Esposo M, Kaushal K, et al. Age-associated impaired plasmacytoid dendritic cell functions lead to decreased CD4 and CD8 T cell immunity. Age (Dordr) 2011; 33(3): 363-76.

[83] Goronzy JJ, Fulbright JW, Crowson CS, Poland GA, O'Fallon WM, Weyand CM. Value of immunological markers in predicting responsiveness to influenza vaccination in elderly individuals. J Virol 2001; 75: 12182-7.

[84] Goronzy JJ, Lee WW, Weyand CM. Aging and T-cell diversity. Exp Gerontol 2007; 42: 400-6.

[85] Gupta S, Bi R, Su K, Yel L, Chiplunkar S, Gollapudi S. Characterization of naive, memory and effector CD8+ T cells: effect of age. Exp Gerontol 2004; 39: 545-50.

[86] Pawelec G, Akbar A, Caruso C, Solana R, Grubeck-Loebenstein B, Wikby A. Human immunosenescence: is it infectious? Immunol Rev 2005; 205: 257-68.

[87] Pawelec G, Barnett Y, Forsey R, et al. T cells and aging, January 2002 update. Front Biosci 2002; 7: d1056-183.

[88] Vallejo AN. CD28 extinction in human T cells: altered functions and the program of T-cell senescence. Immunol Rev 2005; 205: 158-69.

[89] Olsson J, Wikby A, Johansson B, Lofgren S, Nilsson BO, Ferguson FG. Age-related change in peripheral blood T-lymphocyte subpopulations and cytomegalovirus infection in the very old: the Swedish longitudinal OCTO immune study. Mech Ageing Dev 2000; 121: 187-201.

[90] Pawelec G, Derhovanessian E, Larbi A, Strindhall J, Wikby A. Cytomegalovirus and human immunosenescence. Rev Med Virol 2009; 19: 47-56.

[91] Chong Y, Ikematsu H, Yamaji K, et al. CD27(+) (memory) B cell decrease and apoptosis-resistant CD27(-) (naive) B cell increase in aged humans: implications for age-related peripheral B cell developmental disturbances. Int Immunol 2005; 17: 383-90.

[92] Frasca D, Diaz A, Romero M, Landin AM, Blomberg BB. Age effects on B cells and humoral immunity in humans. Ageing Res Rev 2011; 10(3): 330-5.

[93] Frasca D, Blomberg BB. Effects of aging on B cell function. Curr Opin in Immunol 2009; 21: 425-30.

[94] Linton PJ, Dorshkind K. Age-related changes in lymphocyte development and function. Nat Immunol 2004; 5: 133-9.

[95] Saurwein-Teissl M, Lung TL, Marx F, et al. Lack of antibody production following immunization in old age: association with CD8(+)CD28(-) T cell clonal expansions and an imbalance in the production of Th1 and Th2 cytokines. J Immunol 2002; 168: 58939.

[96] Shahid Z, Kleppinger A, Gentleman B, Falsey AR, McElhaney JE. Clinical and immunologic predictors of influenza illness among vaccinated older adults. Vaccine 2010; 28: 6145-51. 
[97] Frasca D, Diaz A, Romero M, et al. Intrinsic defects in B cell response to seasonal influenza vaccination in elderly humans. Vaccine 2010; 28(51): 8077-84.

[98] Amanna IJ, Carlson NE, Slifka MK. Duration of humoral immunity to common viral and vaccine antigens. N Engl J Med 2007; 357: 1903-15.

[99] Bernasconi NL, Traggiai E, Lanzavecchia A. Maintenance of serological memory by polyclonal activation of human memory B cells. Science 2002; 298: 2199-202.
[100] Manz RA, Radbruch A. Plasma cells for a lifetime? Eur J Immunol 2002; 32: 923-7.

[101] Sasaki S, Jaimes MC, Holmes TH, et al. Comparison of the influenza virus-specific effector and memory B-cell responses to immunization of children and adults with live attenuated or inactivated influenza virus vaccines. J Virol 2007; 81: 215-28.

[102] Sasaki S, Sullivan M, Narvaez CF, et al. Limited efficacy of inactivated influenza vaccine in elderly individuals is associated with decreased production of vaccine-specific antibodies. J Clin Invest 2011;121(8): 3109-19.

Received: May 08, 2011

Revised: September 08, 2011

Accepted: October 18, 2011

(C) Blomberg et al.; Licensee Bentham Open.

This is an open access article licensed under the terms of the Creative Commons Attribution Non-Commercial License (http://creativecommons.org/licenses/by-nc/3.0/) which permits unrestricted, non-commercial use, distribution and reproduction in any medium, provided the work is properly cited. 